\title{
Modelos de categorização: apresentando o modelo clássico e o modelo de protótipos
}

\author{
Gercina Ângela Borém de Oliveira Lima
}

\author{
Doutora em Ciência da Informação \\ pela ECI/ UFMG. Professora da \\ Escola de Ciência da Informação da \\ UFMG
}

Este trabalho apresenta um estudo preliminar sobre os modelos de categorização clássicos e de protótipos. 0 modelo clássico de categorização do conhecimento é baseado nas idéias aristotélicas e o modelo de protótipos de categorização elaborado por Eleanor Rosch, na década de 1970. Confrontam-se as posições antagonistas do modelo clássico e do modelo de protótipo: a primeira, na qual as categorias são definidas somente pelas propriedades que todos os membros da classe possuem; a segunda, na qual alguns membros condensam melhor os traços mais característicos da categoria.

Palavras-chave: Categorização; Ciências cognitivas; Modelo clássico de categorização; Modelo de protótipo de categorização.

\section{Categorization models: presenting the classic and prototype models}

This is a preliminary study about the classic and prototype models of categorization. The classic model of knowledge categorization is based on the Aristotelian ideas and the prototype model of categorization was elaborated by Eleanor Rosch, a cognitive researcher, in the 1970s. The antagonistic positions of the classic and the prototype model are confronted; the former with the categories defined only by the properties shared by all members of the class, and the latter, where the most characteristic features of the category are condensed in some members

Keywords: Categorization; Cognitive sciences; Prototype categorization model; Classic categorization model. 


\section{Introdução}

Embora o foco deste trabalho esteja na descrição dos modelos de categorização, confrontando as posições antagonistas do modelo clássico e do modelo de protótipo, apresentarei primeiro algumas definições sobre categorização/categorias,

Categorizar é agrupar entidades (objetos, idéias, ações, etc.) por semelhança. Para Piedade (1983), autora da área de ciência da informação, esse é um processo mental habitual do homem, pois vivemos automaticamente classificando coisas e idéias, a fim de compreender e conhecer. São apresentadas, a seguir, definições de categorização que a caracterizam como processo cognitivo. Segundo Lakoff (1987, p. 5):

A maioria de nossas palavras e conceitos designam categorias [...] Categorização não é um processo que deve ser estudado superficialmente. Não há nada mais básico do que a categorização para o nosso pensamento, percepção, ação, e discurso. Cada vez que nós vemos algo como "um tipo" de coisa, por exemplo, uma árvore, nós estamos categorizando. [...] A compreensão de como categorizamos é o ponto central para a compreensão de como nós pensamos, funcionamos e, conseqüentemente, um ponto central para a compreensão daquilo que nos faz humanos.

Jacob e Shaw (1998, p. 155) dizem que "categorização é um processo cognitivo de dividir as experiências do mundo em grupos de entidades, ou categorias, para construir uma ordem física e social do mundo". Markman (1989) ${ }^{1}$, citado por Jacob e Shaw (1998, p. 155), descreve a categorização como "um mecanismo fundamental que simplifica a interação individual com o ambiente: não somente facilitando - armazenamento e a recuperação da informação, mas, também, reduzindo a demanda da memória humana". Finalmente, para Gardner (1996, p. 373), "as categorias têm uma estrutura interna, centrada em protótipos ou estereótipos, e outros exemplares são definidos como mais ou menos periféricos, dependendo do grau em que eles compartilham características cruciais com o protótipo central".

Desde a época de Aristóteles, já havia a preocupação com as práticas de nomear, definir e categorizar. Com o desenvolvimento de estudos na ciência cognitiva, a visão de como categorizamos sofreu modificações. A categorização passou de um processo cognitivo individual a um processo cultural e social de construção da realidade, que organiza conceitos, parcialmente baseados na psicologia do pensamento. A informação perceptiva é fundamental na definição das extensões de uma

\footnotetext{
${ }^{1}$ MARKMAN, E. M. Categorization and naming in children: problems of induction. Cambridge, MA: MIT Press, 1989. $250 \mathrm{p}$.
} 
categoria, porque a categorização não é feita artificialmente, mas, sim, levando-se em conta as informações do mundo a que pertencemos e como respondemos a elas. Na categorização, o reconhecimento das similaridades e diferenças leva à criação de um conhecimento novo, pelo agrupamento de entidades, de acordo com as similaridades e diferenças observadas.

Nota-se que um aspecto essencial da cognição é a habilidade de categorizar: julgar que uma coisa particular é ou não um exemplo de uma categoria particular. Porém, o problema em compreender que critérios são usados para agrupar as entidades em uma mesma categoria, sendo que nesse processo as entidades distintas são tratadas como equivalentes, faz a categorização ser considerada como um dos principais processos cognitivos.

Sabe-se que as Ciências Cognitivas têm como objeto de estudo os processos gerais que regem a percepção, a organização, o armazenamento, a recuperação e a utilização da informação, bem como as formas como se organiza a representação dessas atividades no tratamento da informação. A organização conceitual, que está diretamente relacionada à capacidade de aprender, supõe a assimilação de novas informações, sua estocagem e sua acomodação.

\section{Categorização como processo cognitivo}

Categorizar coisas é inerente aos seres humanos desde os primeiros momentos de vida, porque o cérebro dá forma às estruturas que espelham o ambiente externo em uma forma categorial. Nota-se que toda essa classificação vem de nossa interação com nosso ambiente. Se nós não interagirmos com o ambiente, nós não teremos o que classificar; o ambiente influencia muito no modo como nós categorizamos a informação. Assim, dependendo do ambiente em que estamos, as categorias podem mudar para refletir o ponto de vista de uma informação, em determinado contexto. De acordo com Lakoff (1986, p. 5), não existe nada mais básico do que a categorização para o nosso pensamento, nossa percepção, ação e fala. Todas as vezes que vemos alguma coisa como um tipo de coisa, ou como parte de alguma coisa, nós estamos categorizando. Isso ocorre, principalmente, pelas características oriundas das similaridades e diferenças existentes entre conceitos, dentro de determinado contexto. A elaboração de categorias geralmente é referida como uma metodologia na qual conceitos formam novas categorias pelas características inerentes a eles próprios.

Uma das principais funções da mente é interpretar o significado das informações adquiridas e transformá-las em conhecimento, o que se torna mais fácil quando tais informações são apresentadas em formato gráfico. Segundo Moreira (1993, p. 33), a estruturação do conhecimento na mente humana tende a seguir uma estrutura hierárquica, a partir das ideias mais abrangentes. A categorização como processo cognitivo é uma alternativa de estruturar a informação, pois ela procura refletir a organização da estrutura informacional de uma pessoa sobre determinado assunto. Essas 
estruturas do conhecimento são representações da organização das ideias na nossa memória semântica. Cada estrutura de conhecimento existe como objeto, ideia ou evento e, também, como um grupo de atributos, o qual é ligado à outra estrutura do conhecimento. À medida que aprendemos, apreendemos novas estruturas e ligações, adicionando informações às estruturas existentes, ou alterando essas estruturas através do processo de reestruturação.

Nosso conhecimento reside na memória semântica, a qual Eklund (1995, p. 4) define como uma rede de conceitos inter-relacionados. Os processos cognitivos são atividades mentais como o pensamento, a imaginação, a lembrança e a solução de problemas (ALLEN, 1991, p. 13). Como ocorre em outras situações humanas, essas atividades são desempenhadas por indivíduos que têm níveis diferentes de habilidade em raciocínio lógico e em memória visual, o que pode afetar o desempenho na recuperação da informação. A cognição humana é essencialmente organizada como uma rede semântica, na qual os conceitos são ligados pelas associações.

As funções da categorização do ponto de vista cognitivo são: (a) classificar, que é a função que permite que a mente faça contato com o mundo; (b) dar apoio a explanações e assegurar prognóstico em relação ao futuro, o qual pode ser utilizado para selecionar planos e ações; e (c) dar sustentação à mente, pois não há necessidade de armazenar todos os fatos e suas possibilidades, se as inferências podem ser derivadas de informações já armazenadas (MEDIN; ROSS, 1996).

\section{Modelos cognitivos de categorização}

Segundo Koch (2002, p. 67), o desafio básico da ciência cognitiva é tentar entender e esclarecer como o homem representa mentalmente o mundo geral e o específico que o cercam e que estruturas da mente possibilitam as atividades cognitivas. Considerando-se que a cognição apresenta-se sob a forma de representações (conhecimentos estabilizados na memória e suas interpretações) e processamento das informações (processos voltados para a compreensão e a ação), é necessário distinguir, dentro do processo cognitivo, o que é provisório e o que é permanente.

Geralmente, os cientistas cognitivos que estudam conceitos estão preocupados com três questões: como os conceitos são representados, como nós classificamos os exemplos pertencentes a um conceito e como nós elaboramos os conceitos em nossa mente. Mas, os cientistas cognitivistas não foram os primeiros a se preocupar com essas questões. Nota-se que este problema tem uma tradição filosófica. Desde a época de Platão e de Aristóteles, a natureza dos conceitos, em suas representações, como nós reconhecemos os exemplos de conceitos específicos e como nós interpretamos os conceitos, são questões entre as mais estudadas na filosofia. Esta visão, em que os conceitos eram constituídos por um ou mais elementos presentes em todos os objetos, e em que os conceitos são definidos por um conjunto de características necessárias e suficientes para 
descrevê-los, é considerada, dentro da psicologia cognitiva, por alguns autores, como uma espécie de conceitualismo, chamado de modelo clássico por Jerome Bruner (1956).

Para Gardner (1996, p. 361), alguma variante dessa posição clássica foi amplamente sustentada até meados do século $X X$, quando essa concepção de categorização teve repercussão na psicologia, através de estudos pioneiros, desde os anos 20, por Hull (1920), culminando na proposta de outros três modelos:

(1) Modelo probabilístico, que usa a representação descritiva incorporando probabilidades que os membros tenham uma característica em particular;

(2) Modelo exemplar, que usa descrições das formas típicas dos membros; e

(3) Modelo de protótipo, em que, basicamente, alguns elementos são considerados melhores representantes de uma categoria do que de outra. Mostra-se, também, que a maioria das categorias não pode ser definida por uma mera lista das propriedades compartilhadas por todos os elementos.

As similaridades estruturais entre esses quatro modelos não estão explícitos na literatura, mas, o Prof. Douglas Medin, do Department of Psychology of Northwestern University Evanston, IL, USA, um dos autores do livro Categories and concepts, em correspondência via e-mail, de agosto de 2006, afirma que o modelo exemplar e o modelo de protótipo são variações do modelo probabilístico. Assim, neste capítulo, serão descritos apenas o modelo clássico (que compartilha a maior parte dos princípios dos dois primeiros modelos) e o modelo de protótipo (que engloba importantes aspectos dos dois últimos). Passa-se, então, a descrever o modelo clássico e o de protótipo.

\subsection{O Modelo Clássico}

De acordo com Smith e Medin (1981, p. 22), a visão clássica é uma teoria psicológica sobre como os conceitos são representados na espécie humana e em outras espécies. Na filosofia, a origem dessa visão remonta a Aristóteles; na psicologia experimental essa visão foi traçada através da pesquisa de Hull (1920) sobre estabelecimentos de conceitos. Tanto para Platão como para Aristóteles, os conceitos são definidos por suas essências. Enquanto que o estudo de Platão foca nas formas ideais, o que o distanciou da teoria científica sobre conceitos, muitos estudiosos, na metade do século 20, baseavam seus estudos nas ideias de Aristóteles, tratando os conceitos como sendo definidos por um jogo de características necessárias e suficientes, que eram descobertas empiricamente, sendo uma proposta de representação e não de processo.

A teoria clássica de Aristóteles é considerada por alguns como a hierarquia perfeita do mundo. Nela, as categorias são definidas apenas pelas propriedades comuns a todos os seus membros. Desta forma, 
nenhum membro pode ser considerado melhor exemplo da categoria que os demais. As categorias são definidas apenas pelas propriedades inerentes os seus membros. Assim, elas devem ser independentes de quem estiver categorizando, ou seja, ela não deve ser influenciada pelos movimentos do corpo humano, pela neurofisiologia humana, pelas capacidades humanas de percepção, pelo aprendizado, pela lembrança, pela comunicação ou por fatores sócio-culturais. A teoria clássica fornece uma explicação direta para o fato de separarmos membros e nãomembros de uma categoria. Os membros de uma categoria são justamente aqueles objetos, ou exemplares, que exibem as características necessárias e suficientes que definem a categoria; e os que não exibirem essas características são considerados não-membros, possibilitando, também, uma formação intuitiva do conceito. Formamos conceitos quando temos vários membros de um grupo, e determinamos as características únicas que dividem esses membros em classes separadas. Assim, nesse modelo, está claramente demarcado o que constitui ou não um exemplar de uma categoria, cujas fronteiras estão claramente definidas. Quando as categorias são organizadas em hierarquias, as categorias mais específicas incluem todos os atributos das categorias mais gerais. Suponha que você tenha um conceito mais específico, "canário" (definido como emplumado, animado, bípede, pequeno, marrom), e o superordenado (mais geral) "pássaro" (definido como emplumado, animado, bípede). Essa concepção de categorização deve bastante ao trabalho pioneiro realizado na filosofia e na lógica, nomeadamente por Frege (1952). Ele sustenta que um conceito pode ser caracterizado por um conjunto de atributos de definição, que ele chamou de intensão. A intensão é composta pelo conjunto de atributos que definem as necessidades para ser um membro daquele conceito, e pela extensão, que é o conjunto de entidades que são membros daquele conceito, ou seja, por um número de exemplares que o formam.

Collins e Quillian (1969, p. 241) afirmam que os estudos sobre redes semânticas nos anos 60 e 70 mostraram como a teoria clássica permite uma maneira fácil de construir relacionamentos taxonômicos entre os conceitos. Os membros de uma taxonomia são relacionados por suas características necessárias e suficientes, com mais membros subordinados que estão sendo definidos pelas mesmas características que definem seus superordenados, como se tratasse de um jogo de "tudo ou nada", sempre se aplicando características que vão separando elementos pelas distinções e, consequentemente, formando outros grupos, não havendo nenhum representante preferido dentro de uma categoria, pois todos os membros têm uma posição de igualdade.

As características definidoras do modelo clássico são apontadas por Smith e Medin (1981) no livro Categories and Concepts:

(a) as categorias são arbitrárias. Itens podem ser agrupados de inúmeras maneiras para formar categorias, e as pessoas podem aprender a identificar ou construir essas categorias definidas pela sua cultura, pois 
nada no mundo ou em nosso sistema nervoso determina como devemos repartir as nossas observações;

(b) as categorias possuem atributos definidores ou críticos. Todos os membros de uma categoria compartilham destes atributos definidores, nenhum não-membro compartilha deles, e não há sobreposição entre membros e não membros;

(c) a intensão (ou conjunto de atributos) determina a extensão de uma categoria (quais itens são membros). De maneira que não faz sentido falar que uma categoria tem uma estrutura interna, com alguns itens se destacando como membros melhores do que outros itens.

Além dessas características, o modelo clássico baseia-se em três pressupostos, que, apesar de não serem os únicos usados pelos estudiosos da área, são os que mais foram utilizados, principalmente pelos principais trabalhos do ponto de vista da psicologia, abordando a temática sobre conceitos de 1920 até 1970 (SMITH; MEDIN,1981, p. 23). Os três pressupostos são:

(1) a representação dos conceitos, que envolve descrição sumária da classe; cada conceito possui definições que vão caracterizá-los e determinar se tal elemento pertence ou não àquela classe. Por exemplo, o chipanzé é um animal mamífero? Faça-se uma comparação das características de um chipanzé com a representação sumária, ou conjunto de definições que o caracterizariam como um animal mamífero. Pode-se observar que os mamíferos se alimentam de leite, têm pelos, e procriam; o chipanzé possui essas características; então o chipanzé é um animal mamífero;

(2) as características definidoras de uma categoria precisam ser tanto individualmente necessárias quanto suficientemente agrupadas, para definir a categoria. Um objeto deve ter quatro lados, dois lados de tamanho igual e de ângulos iguais para ser uma figura fechada e ser categorizada como um retângulo; se algum destes lados for diferente, a figura não é um retângulo. Qualquer outra propriedade dos retângulos como, por exemplo, onde ele está desenhado, e qual o material utilizado para desenhá-lo não importa, somente a definição das características determina se ele pertence ou não àquela categoria;

(3) categorias são agrupadas, destacando-se que a categoria subordinada possui todas as características da categoria supra-ordenada. Quando se determina que um objeto possui todas as características que o faz ser reconhecido como uma "rosa", por exemplo, sabemos que ele tem, também, todas as características definidoras para "flores", para "plantas" e para ser uma "coisa viva".

Apesar de o modelo clássico ter tido uma grande repercussão em várias áreas do conhecimento, seus pressupostos têm recebido várias críticas através dos anos. Nota-se, através da literatura, que aumentou o número de estudos sobre categorização, com surgimento de novas disciplinas, e, consequentemente, com isso, começaram a ser apontados problemas gerais em relação à teoria clássica. Algumas críticas 
pertinentes são apresentadas em vários trabalhos e alguns serão citados aqui.

Lakoff $(1987$, p. 6) destaca que a teoria clássica não é o resultado de um estudo empírico, e vai mais além, quando afirma que ela não era um assunto de debates. De fato, até recentemente, a teoria clássica de categorias não era nem pensada como teoria. Era vista, na maioria das disciplinas, como uma verdade definida e inquestionável, e não como uma hipótese empírica.

Algumas objeções bastante pertinentes também foram apontadas por Smith e Medin (1981, p.162):

(1) a existência de conceitos disjuntivos (a qual é interditada na visão que supõe as características como definidoras);

(2) a existência de casos confusos (difíceis de reconciliar, na visão que supõe que as características definidoras de um conceito estão aninhadas dentro daquelas de seus subordinados); e

(3) a insuficiência geral em especificar características definidoras para a maioria dos conceitos.

Outros problemas mais ligados a resultados experimentais são:

(1) a ocorrência de efeitos de tipificação simples (em que um maior número de membros típicos são categorizados com mais eficiência);

(2) a correlação entre semelhanças de tipificação e de famílias;

(3) o uso de características não necessárias, na categorização; e

(4) a descoberta de que os conceitos, às vezes, são julgados como mais similares (e categorizados mais rapidamente como um membro pertencente a) aos seus conceitos distantes do que seus superordenados imediatos.

Já Eysenck e Keane (1990, p. 229) fazem duas críticas:

(1) a teoria clássica não consegue captar aspectos significativos do comportamento conceptual; e

(2) a concepção central deste ponto de vista, de que os conceitos dependem de uma conjunção de características essenciais, simplesmente está errada.

De acordo com as colocações desses autores, pode-se dizer que o modelo clássico falha na captação de aspectos significativos do comportamento conceitual e não se pode dizer que os conceitos dependem de uma conjunção de atributos necessários. Nota-se que, apesar de estudos feitos por várias gerações de linguistas, filósofos e psicólogos, não é fácil determinar os atributos que definam a maioria dos conceitos, com a argumentação de que toda a tentativa de dividir os conceitos em atributos essenciais e auto-suficientes é fundamentalmente 
mal concebida, pois alguns conceitos simplesmente parecem não ter nenhum atributo que os defina.

\subsection{O Modelo de Protótipo}

De acordo com Eysenk e Keane (1990), a Teoria de Protótipos foi proposta especificamente para explicitar as deficiências do ponto de vista de definição de atributos. Segundo Murphy (2002, p. 73) a maior crítica vinda dos teóricos do modelo de protótipos em relação ao modelo clássico era sobre a necessidade e a suficiência das propriedades das classes, mas não questionava a noção da representação do conceito: "cães" é a descrição que se aplica a todos os cães, em geral. No modelo clássico, um sumário de definições de atributos é necessário para quantificar as características dos membros, como, por exemplo, "todos os cães têm quatro patas". Assim, para esses estudiosos, existem poucas características que todos os membros de uma categoria têm, mas a sua representação envolve uma lista geral de características que a maioria ou muitos dos membros possuem; e essa lista é a descrição da categoria e não dos membros em particular.

Foi Eleanor Rosch quem transformou a categorização em uma questão de pesquisa. Desenvolvendo seus trabalhos na década de 70, criou o modelo de protótipo baseado na tese de que, se no modelo clássico as categorias são definidas somente pelas propriedades que todos os membros da classe possuem, então nenhum membro pode exemplificar a categoria melhor que outro (ROSCH, 1975; 1978). O princípio fundamental deste modelo sustenta que as categorias são organizadas em torno de protótipos centrais. Um item é considerado como membro de uma categoria não por se saber que ele possui um determinado atributo ou não, mas por se considerar o quanto as dimensões desse membro se aproximam das dimensões ideais para ele. Em outras palavras, um exemplo representativo de uma classe seria aquele que compartilhasse com os outros membros da categoria do maior número de características e que, por outro lado, compartilhasse de poucas características (ou nenhuma) com elementos provenientes de fora da classe. De acordo com o modelo de protótipo, conceitos são representados por um grupo de características, e não por suas definições. Um novo membro é categorizado como um tipo de conceito se é suficientemente similar ao seu protótipo. O agrupamento de conceitos em uma dada categoria se daria, segundo a pesquisadora, não pela alternância dos traços binários, mas pela semelhança com o protótipo, em que o membro condensasse os traços mais característicos da categoria. Um pintarroxo é uma ave mais prototípica do que uma galinha ou um pinguim; o que o faz ser mais facilmente reconhecido como uma ave e menos provável que seja classificado erroneamente como membro de outra categoria (tal como um mamífero ou peixe) (GARDNER, 1996, p. 365)

Rosch e Mervis (1975) mostraram que quanto mais prototipicamente um membro de uma categoria é julgado, maior será a 
quantidade de características comuns que ele terá com os outros membros desta categoria, e menos atributos comuns com membros de categorias contrastantes. Em resumo, protótipos são justamente aqueles membros de uma categoria que mais refletem a redundância da estrutura de uma categoria como um todo. Assim, um canário é protótipo de um pássaro, mas uma galinha não é.

Segundo Kleiber (1990), essa concepção se apoiava sobre as seguintes teses:

(a) a categoria tem uma estrutura interna prototípica;

(b) o grau de representatividade de um exemplar corresponde ao seu grau de vinculação à categoria;

(c) as fronteiras das categorias ou dos conceitos são imprecisas;

(d) todos os membros de uma categoria não apresentam as mesmas propriedades comuns;

(e) o preenchimento de uma categoria se efetua sobre a base do grau de similaridade com o protótipo;

(f) a similaridade não se opera de maneira analítica, mas de modo global.

Desse modo, compartilhando traços típicos, um pardal seria o protótipo da categoria pássaro, a águia seria um membro intermediário e o pinguim, periférico.

Nessa perspectiva, os objetos e fatos do mundo apresentariam propriedades acidentais, irrelevantes para a categorização (o fato de um cachorro ser branco, marrom ou preto, por exemplo), e propriedades essenciais, fundamentais para a categorização (o fato de um cachorro ter patas, ter cauda e latir, por exemplo). A simples combinatória dos traços essenciais permitiria o mapeamento do mundo, encerrando-se, sob o termo representação, a ideia de que a mente reflete a estrutura previamente existente no mundo.

Os princípios norteadores do modelo de protótipo são apresentados por Eysenk e Keane (1990, p. 235):

1. As características têm uma estrutura baseada num protótipo;

2. Não há um conjunto delimitador de atributos necessários e suficientes para determinar a inclusão numa categoria. Embora possa haver um conjunto de atributos necessários, eles não são suficientes para a inclusão;

3. Os limites das categorias são imprecisos a ponto de alguns membros poderem pertencer a mais de uma categoria, como acontece, por exemplo, com o tomate em relação a "fruto" e "vegetal";

4. Os exemplares de uma categoria podem ser ordenados em termos do grau de tipicidade que possuem. Existe um gradiente de tipicidade entre os exemplares; 
5. A classificação dos exemplares numa categoria é determinada pela similaridade dos atributos de um objeto com o protótipo da categoria;

6. As categorias são ordenadas, segundo uma hierarquia, em três níveis: superordenados, básicos, subordinados, por exemplo, "fruta", "laranja" e "laranja pêra". Segundo Rosch et al. (1978) estes níveis refletem a melhor maneira como cada um pode organizar um conjunto de categorias.

Existe um volume considerável de pesquisas orientadas para testar modelos de protótipos que se relacionam com a concepção de hierarquias na categorização humana e que obtiveram alguns índices de correlação importantes. Por exemplo, o trabalho pioneiro sobre categorias de nuanças de cores de Eleonor Roch (1975), que foi desenvolvido a partir da grande diversidade de termos para identificar cores nos diversos idiomas do planeta. As culturas possuem um número muito variável de termos para representar toda a gama de cores. Na Europa Ocidental, por exemplo, há uma diversidade de termos para os matizes que vão do magenta ao azul celeste. Em contraste, os danis, povo da Papua-Nova Guiné com características dos povos da idade da pedra, visitados por Rosch (ROSCH, 1973; 1975) nos anos de 1970, têm apenas dois termos para representar nuanças de cores: mola para as coisas claras e quentes e mili para as coisas escuras e frias. Apresentando quarenta fichas de cores em várias tarefas, fichas que incluíam quatro tipos de brilho e dez tipos de matiz, ela verificou que os danis reconheciam as cores muito mais pela "[...] influência de fatores cognitivos perceptivos subjacentes sobre a formação e a referência de categorias lingüísticas" (HEIDER, 1972, p. 20).

Além dessa pesquisa sobre categorias de cores, foram realizadas pesquisas sobre as categorias naturais, como aves e móveis, que fornecem evidências sobre o aspecto de protótipos, nos quais alguns membros são considerados como sendo muito representativos ou típicos, compartilhando um maior número de características entre eles. Foram também realizadas pesquisas sobre as categorias artificiais, como conjuntos de figuras sem sentido, cujos membros foram moldados de acordo com certos critérios pré-determinados.

Essas evidências foram demonstradas através da avaliação do grau de tipicidade dos membros de um conceito, dentro de uma categoria. Por exemplo, na verificação da categoria "ave": "um canário é um pássaro, que é um tipo de ave"; membros típicos (como o corvo, o papagaio, o azulão) são verificados mais rapidamente do que membros atípicos (como o avestruz, que é também um tipo de pássaro que não voa) (SMITH, 1978; SMITH; MEDIN, 1981). Continuando esse raciocínio, pode-se dizer que os membros típicos provavelmente serão primeiros mencionados quando é solicitado aos sujeitos que listem todos os membros de uma categoria (MERVIS; CATLIN; ROSCH, 1976). Outras evidências apontadas por Rosch $(1973 ; 1975)$ foram que: 
(1) os primeiros membros de um conceito que as crianças tendem a aprender são os membros típicos, como medido pelas tarefas de categorização semântica; e

(2) os membros típicos têm uma possibilidade maior de servirem de pontos de referência cognitivos do que os membros atípicos.

Outra evidência apontada por Rosch e Mervis (1975) é a extensão em que as estimativas de semelhança de família se correlacionam com a tipicidade. Os membros típicos têm resultados de semelhança familiares mais elevados, e partilham poucos ou nenhuns atributos com categorias próximas.

Apesar de o modelo de protótipo ser apresentado como uma alternativa ao modelo clássico, muitos críticos questionam se ele pode substituí-lo. Eysenck e Keane (1990, p. 239) apontam as seguintes críticas sobre o modelo de protótipo:

(1) nem todas as categorias têm características prototípicas, apresentado assim, alguns limites no grau de generalidade do modelo; Hampton (1981) examinou tal questão no caso de conceitos abstratos e verificou que alguns destes conceitos exibiram uma estrutura de protótipo e outros não, como "um instinto", "uma crença" e "uma regra". Isto pode ocorrer por causa da existência de grandes flexibilidades em pertencer ou não tais categorias abstratas, diferentemente das categorias concretas;

(2) o ponto de vista do modelo de protótipo é limitado a respeito do conhecimento que as pessoas possuem sobre as relações entre categorias. Por exemplo, as pessoas, além de terem um gradiente de tipicidade da categoria "aves", sabem também que é mais provável que uma ave pequena seja canora do que uma ave grande. Em geral sabe-se que alguns atributos variam mais facilmente do que os outros;

(3) o modelo de protótipo não explica por que as categorias são coerentes. A explicação para isto vem do fato de que algum mecanismo de semelhança é responsável pela coerência da categoria, ou seja, as coisas são agrupadas em categorias porque elas têm certos atributos comuns. Porém, não se pode dizer que a semelhança seja o único mecanismo, pois às vezes formamos categorias que têm um tênue embasamento com atributos compartilhados, mas que, mesmo assim, são coerentes.

Outra visão crítica é apontada por Osberson e Smith (1981) quando asseguram que a teoria do modelo de protótipo não pode explicar as maneiras pelas quais os conceitos complexos (por exemplo, o conceito "peixe de aquário") são aparentemente compostos de conceitos simples. Esses autores propõem uma teoria híbrida, na qual a categorização continue a necessitar de um conceito nuclear, na linha do modelo clássico de conceitos e na qual esse aspecto central deve ser combinado com um processo de identificação (GARDNER, 1996, p. 367). Na visão de Osberson e Smith (1981, p.55), uma teoria híbrida é importante porque "a habilidade para construir pensamentos e conceitos complexos a partir de 
algum armazenamento básico de conceitos parece se encontrar perto do coração da atividade mental humana".

\section{Considerações finais}

A organização da informação é uma das mais antigas e mais pesquisadas áreas da psicologia cognitiva. Sabe-se que, para organizar o conhecimento de qualquer área, da sua representação à sua recuperação, estudam-se primeiramente os conceitos que compõem esse campo do conhecimento e as relações entre eles. A influência do contexto é tão importante na categorização que, qualquer descrição individual na classificação que o desconsidere, pode mostrar-se muito limitada. Categorias e hierarquias de categorias são a melhor maneira de organizar o conhecimento para recuperação, pelo óbvio motivo de que a informação estruturada é mais fácil de ser recuperada do que uma informação desorganizada. O processo de categorização estaria no bojo das questões de interesses das áreas da ciência da informação e da ciência cognitiva, no que tange à estratégia de se classificarem as coisas, fatos e fenômenos existentes, que são objetos da cognição.

As explicações propostas pelos modelos clássicos e de protótipo não são ainda consideradas satisfatórias. É muito difícil estabelecer linhas claras entre os pontos de vistas de cada modelo e os pontos em que são mais satisfatórios. Por um lado, o modelo clássico tem dificuldades em explicar os efeitos da tipicidade; por outro, os modelos alternativos não são capazes de explicar satisfatoriamente a organização das categorias, ou seja, o que faz com que as categorias sejam psicologicamente coesas. Talvez as diferentes naturezas das categorias resultem em tipos diferentes. Pode ser que existam categorias que se adequam melhor ao modelo clássico e outras, ao modelo de protótipo. Uma solução híbrida combinando o aspecto central com um processo de identificação do conceito pode ser ainda considerada a mais eficiente na categorização como um processo cognitivo. Ao invés de conclusivo, este estudo, ao contrário, aponta para a necessidade de um avanço das pesquisas nessa área, para que possamos vislumbrar explicações para as maneiras de como as pessoas formam e utilizam as categorias.

\section{Referências}

ALLEN, B. L. Cognitive research in information science: implications for design. Annual Review of Information Science and technology, v. 26, p.3$37,1991$.

BRUNER, J. S.; AUSTIN, G. A study of thinking. New York: Wiley, 1956.

COLLINS, A. M.; QUILLIAN, M. R. Retrieval time from semantic memory. Journal of Verbal Learning and Verbal Behaviour, v. 8, p. 240-247, 1969. 
EKLUND, J. Cognitive Models for structuring hypermedia and implications for learning from the world-wide web. Disponível em: $<$ http://elmo.scu.edu.au/ sponsored/ausweb95/papers/hypertext/eklund/ index.html>. Acesso em: 15 set. 2002.

EYSENK, M. W; KEANE, M. T. Cognitive psychology: a student's handbook. London: Laurence Erlbaum Associates, 1990.

FREGE, G. On sense and reference. In: GEACH, P.; BLACK, M. (Eds). Translation from the philosophical writings of Gottlob Frege. Oxford: Basil Blackwell, 1952.

GARDNER, H. A nova ciência da mente: uma história da revolução cognitiva. São Paulo: EDUSP, 1996.

HAMPTON, J. An investigation of the nature of abstract concepts. Memory \& cognition, v. 9, p.149-156, 1981.

HEIDER, E. R. Universals in color naming and memory. Journal of Experimental Psychology, v. 93, p.10-20, 1972.

HULL, C. L. Quantitative aspects of the evolution of concepts. Pshicological Monographs, v. 38, n.123, p.1-86, 1920.

JACOB, E. K.; SHAW, D. Sociocognitive perspectives on representation. Annual Review of Information Science and technology, v. 33, p. 131-185, 1998.

KLEIBER, G. La sémantique du prototype: catégories et sens lexical. Paris: Presses Universitaires de France, 1990.

KOCH, I. G. V. Desvendando os segredos do texto. São Paulo: Cortez, 2002. 168 p.

LAKOFF, G. Women, fire, and dangerous things: what categories reveal about the mind. Chicago: The University of Chicago, 1987.

MARKMAN, E. M. Categorization and naming in children: problems of induction. Cambridge, MA: MIT Press, 1989.

MEDIN, D. L; ROSS, B. H. Cognitive psychology. 2 ed. Forth Worth: Harcourt Brace College Publishers,1996.

MERVIS, C. B.; CATLIN, J.; ROSCH, E. Relationship among goodness-ofexample, category norms, and word frequency. Bulletin of the Psychonomic Society, v. 7, n. 3, p. 283-284, 1976.

MOREIRA, M. A. A teoria de educação de Novak e o modelo de ensinoaprendizagem de Gowin. Porto Alegre, RG: IFUFRGS, 1993.

MURPHY, G. L. The big book of concepts. Cambridge: MIT Press, 2002.

OSBERSON, D. N.; SMITH, E. E. On the adequacy of prototype theory as a theory of concepts. Cognition, v. 9, p. 35-58, 1981.

PIEDADE, M. A. R. Introdução à teoria da classificação. Rio de janeiro: Interciência, 1983. 
ROSCH, E. Natural categories. Cognitive Psychology, v. 4, p. 328-350, 1973.

$\mathrm{ROSCH}, \mathrm{E}$. Cognitive representations of semantic categories. Journal of experimental Psychology: General, v. 104, p. 192-233, 1975.

ROSCH, E.; MERVIS, C. B. Family resemblances: studies in the internal structure of categories. Cognitive Psychology, v. 7, p. 573-605, 1975.

ROSCH, E. et al. Principles of categorization. In: ROSCH, E.; LLYOD, B. B. (Eds.). Cognition and categorization. Hillsdale, N.J.: Erlbaum,1978.

ROSCH, E.; LLYOD, B. B. (Eds.). Cognition and categorization. Hillsdale, N.J.: Erlbaum,1978.

RUSSEL, B. A History of Western Philosophy. London: George Allen \& Unwin, 1946.

SMITH, E. E. Theories $f$ semantics memory. In: ESTES, W. K. (Ed.). Hanbook of learning and cognitive processes. Potomac, Md: Erlbaum,1978.

SMITH, E. E.; MEDIN, D. L. Categories and concepts. Cambridge, Massachusetts: Havard University Press, 1981. 